\title{
SIMULATION STUDY OF INDUCTION HEATING OF MULTI-METALLIC INJECTION MOULDS
}

\author{
Mrozek, K. \\ Poznan University of Technology, Faculty of Mechanical Engineering and Management, \\ pl. Marii Skłodowskiej-Curie 5, 60-965 Poznań, Poland \\ E-Mail: krzysztof.mrozek@put.poznan.pl
}

\begin{abstract}
This paper presents a concept and a simulation study into induction heating of multi-metallic injection moulds. This novel technology involves heating only selected cavity walls which are critical areas in forming thin-walled parts. Such regions are often places, where defects occur. In order eliminate the defects, it requires increasing the temperature of selected critical forming walls within a single cavity. In this work, simplified models of forming inserts of different shapes were created. Walls intended for induction heating were selected and separated. Forming cavities were defined as paramagnetic materials, whereas, heated walls were made of ferromagnetic steel 1.2343. Induction coil was placed 1 - $5 \mathrm{~mm}$ away from the wall. As a current source $10 \mathrm{~kW}$ induction generator EFD Minac 6 was used. The current frequency was $25 \mathrm{kHz}$. The obtained results show that it is possible, without a significant cycle time growth, to dynamically increase the temperature of selected walls by applying selective induction heating technology.

(Received in July 2017, accepted in January 2018. This paper was with the author 2 weeks for 1 revision.)
\end{abstract}

Key Words: Injection Moulding, Induction Heating, Selective Heating, Multi-metallic Mould

\section{INTRODUCTION}

At present, there exist various methods of heating induction moulds that operate in dynamic temperature cycles [1-3]. In spite of marketing information, there is not a one universal technology that can satisfy all the requirements set by the entire industry. This leads to the situation where many commercial R\&D institutions and academic centres, all around the world, work intensively on the development of new dynamic methods of heating forming surfaces [4-10].

In the last few years, the fastest developing technology of rapid heating cycle injection is induction heating. The first patent application, that described that technology as an effective mean of parts quality improvement, was filed by Wada et al. [11]. The authors of the application presented the initial results of their research indicating a great potential of that method. With an increase of manufacturing efficiencies and a constant demand for better quality, after year 2000, numerous papers appeared that concerned induction heating of injection moulds. The most famous research centre in the field of inductively heated moulds is Chung Yuan Christian University in Taiwan. Chen et al. conducts extensive research into improvement of efficiency and stability of the process [2, 12-14]. Their main success was to achieve high and uniformly distributed temperature of the forming surfaces inside the cavity at a very short time. Their work was based on the thesis that it was the most important to maintain stable physical parameters during injection at every part of the mould. Induction heating of the entire forming surface involves generation and flow of high amount of energy and long heating time. As a consequence, the production cycle time increases as well.

The author, during his work on a research project, developed a new original method in which selected forming surfaces of injection mould are heated locally. The principle of that method is to identify the forming surfaces that are responsible for creation of product defects and to rise their temperatures up to melting point of injected plastic [15]. The increase of temperatures allows the avoidance of basic defects that are caused by excessive cooling of the 
flowing material: short shots, visible welding lines, diesel effect, warping, etc. which was presented in the article [16]. In this publication the author develops issues related to the heating process itself.

For induction heating, an external induction coil was used that was installed on the dedicated pneumatic manipulator and connected to a Minac 6 generator. The coil was fitted with magnetic flux concentrator that significantly improved the efficiency of the process [17]. Separation of inductively heated surfaces from the other part of the cavity that is not heated is achieved by moveable forming inserts which moves in the direction of the coil once the mould is open. During the project three prototypes of injection moulds heated by induction were built and tested using thermo-vision camera.

The obtained simulation and experimental results as well as production trials proved that: heating of selected surfaces by induction allows effective and energy-efficient injection with dynamically varied temperature inside the mould. It was also proved that application of the developed technology for manufacturing thin-walled products does not increase the time of cooling down the tool in comparison to conventional (isothermal) process. In addition, local induction heating of selected forming surfaces enables elimination of visible welding lines and other typical defects of thin-walled products (wall thickness $<0.5 \mathrm{~mm}$ ). By increasing forming walls temperature, premature freezing of the melt can be stopped. This allows complete filling of the cavity and copying microstructural patterns on the part surface what was presented by Huang, Theilade, Xie et al. [3, 18, 19] as well. As a consequence, enhanced surface is achieved (better surface quality) together with lower resistance to polymer flow [20]. On the other hand, when the mould is closed, more uniform distribution of pressure inside the produced part is obtained. This leads to lower pressure gradient between the gate and most distant areas of the cavity, what causes the internal stress reduction and shrinkage. This is evident especially when temperatures of both sides of the mould are dynamically controlled.

The purpose of the publication is to present a novel innovative technology of injection moulding using multi-metallic injection moulds selectively heated by induction. The main idea of this project is inductively heat/re-heat only cavity walls that are responsible for defect creation or in case high performance and surface quality of produced part is required. Areas of special interest are narrow sections such thinned walls, living hinges, straps and snaps. As it has been proved [15-17], concentration of magnetic field at selected surfaces would improve the dynamics of heating process as well as reduce energy consumption in comparison to current induction heating solutions. Local temperature increase, in relation to heating the entire volume, would be beneficial for injection cycle time, as cooling time would be reduced. It is assumed that the application of this technology would provide a lot of benefits. The main advantage of the technology is the possibility of control of the magnetic field lines by application of different materials in one cavity insert. Forming walls of which high temperature is desired will be made of material is suitable for induction heating (ferromagnetic steel of certain magnetic permeability, resistance and thermal conductivity). The other areas of the cavity will be made of paramagnetic material in order to make them less susceptible to magnetic field.

\section{SELECTIVE INDUCTION HEATING}

Induction heating is a commonly used process in the modern industry. This technology is used in metal hardening, hot working, casting and, more frequently, for dynamic temperature control of injection moulds. With a reference to alternative methods, electromagnetic induction allows achievement of high temperature at very short time [21]. 
Due to the multitude of nonlinear relations among particular parameters, it is difficult to precisely predict the exact temperature values during induction heating [22]. Moreover, material parameters are not the only factors affecting the induction heating. Internal stress caused by machining [23] or heat treatment may significantly influence the dynamics of the process. In order to solve the electromagnetic problem, Maxwell equations are used (Fig. 1) [24]. Additional supplementing equation might be described as (1-3):

$$
\begin{aligned}
& J=\sigma E \\
& B=\mu H \\
& D=\varepsilon E
\end{aligned}
$$

where: $J$ is current density, $\sigma$ is conductivity, $E$ is electric field intensity, $B$ is magnetic field, $\mu$ is magnetic permeability, $H$ is magnetic field intensity, $D$ is electric flux density, $\varepsilon$ is dielectric constant.

According to Eom and Park, Maxwell's equations can be replaced with the Eq. (4) by introducing the magnetic vector potential $A$ in time $t$ [25]:

$$
\frac{1}{\mu} \nabla \times \nabla \times \mathrm{A}-\sigma \frac{\partial A}{\partial t}=0
$$

Eq. (4) was discretize, which allowed it to be used for finite element simulation of an electromagnetic field analysis. The change of the temperature in the heated area of a mould is then figured by solving the transient heat conduction Eq. (5):

$$
\nabla \cdot[k(T) \nabla T]+\dot{q}=\rho_{m} C(T) \frac{\partial T}{\partial t}
$$

where: $k$ is thermal conductivity, $T$ is temperature, $\rho_{m}$ is material density, $C$ is specific heat.

In the FEM programs, the heat generating rate $\dot{q}$ is described by function of current density and resistivity as it is presented in Fig. 1, where $R e$ denotes real component. The skin depth from the mould surface, covering most of the induced current, is defined as $\delta$ [26].

The present study deals with the issue of selective induction heating of injection moulds through application of multi-metallic cavity inserts. The process in question consists in exclusive increase in temperature of selected forming surfaces, expected to be the most problematic with regard to defect generation in the manufactured product.

\section{SIMULATION RESEARCH}

In order to conduct a simulation study of heating process of multi-metallic induction heating, we used FEM software. For that purpose, the algorithm developed by Chen [2, 12-14] was modified by taking into account the temperature in the process of electromagnetic analysis. That was solved by creating a single file containing information about geometry, material database, FEM mesh, physical properties and relations between corresponding physical parameters.

The simulation was conducted for initial temperature of $50{ }^{\circ} \mathrm{C}$, what corresponds to an average temperature of a conventional thermostatic induction mould and air within the close surrounding of a tool. In the study, electrical current of $1000 \mathrm{~A}$ and $25 \mathrm{kHz}$ frequency flowed through copper-made induction coil, which diameter and thickness were $10 \mathrm{~mm}$ and $1 \mathrm{~mm}$ respectively. High current frequencies are desired due to the accompanying skin effect occurring during induction heating. Namely, the higher the frequency of current, flowing through the coil, the smaller the penetration depth of the magnetic field lines into the heated material. 


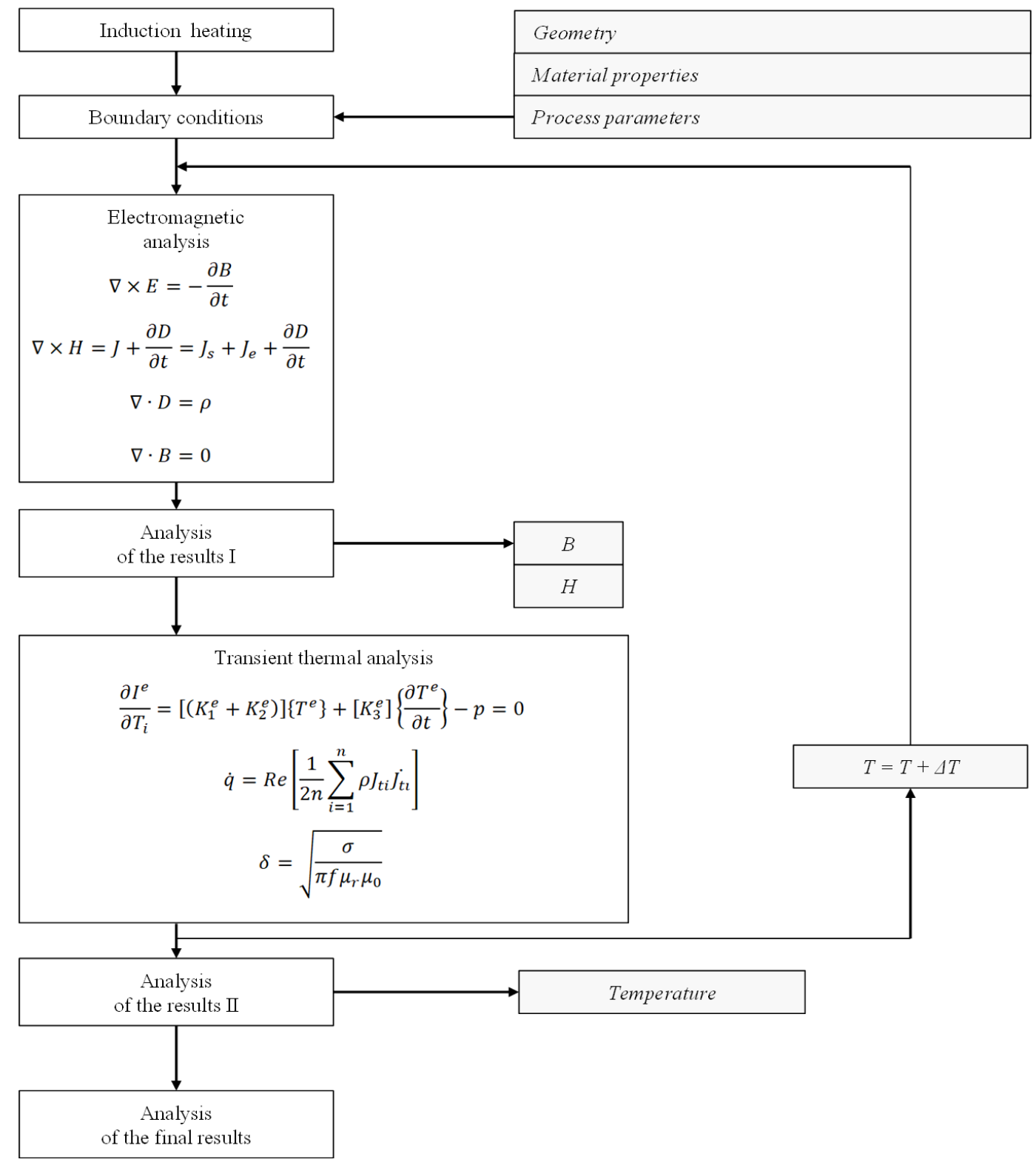

Figure 1: Algorithm to be used for conducting the simulation study, where: $J$ - current density, $J_{s}-$ source current vector, $J_{e}$ - induction current vector, $I^{e}$ - current density, $K$ - coefficient matrices, $J_{t i}$ - current density in element, $J_{t i}{ }^{*}$ - conjugate values of current density, $\delta$ - skin depth, $f$ - current frequency, $\mu_{r}$ - relative magnetic permeability of the conductor, $\mu_{0}-$ permeability of free space.

Table I: The most important material parameters used in simulation study.

\begin{tabular}{|l|c|c|c|c|}
\hline Material & $\boldsymbol{\mu}_{\boldsymbol{r}}$ & $\boldsymbol{\sigma}(\mathrm{S} / \mathrm{m})$ & $\boldsymbol{K}(\mathrm{W} / \mathrm{mK})$ & $\boldsymbol{C}(\mathrm{J} / \mathrm{kgK})$ \\
\hline Air & 1 & $5 \mathrm{e}^{-15}$ & 0.025 & 1005 \\
\hline Water & 1 & $2 \mathrm{e}^{-4}$ & 0.58 & 4190 \\
\hline $\mathrm{Al}$ (PA9) & 1 & $3 \mathrm{e}^{7}$ & 150 & 850 \\
\hline $\mathrm{Cu}$ & 1 & $5.6 \mathrm{e}^{7}$ & 380 & 380 \\
\hline 1.2343 & 55 & $10^{7}$ & 45 & 460 \\
\hline Fluxtrol A & 130 & $5 \mathrm{e}^{-5}$ & 23 & 430 \\
\hline
\end{tabular}

In the conducted studies, seven various scenarios concerning induction heating of forming cavities using electromagnetic induction were analysed. Simulations were conducted for 2dimensional cross-section normal to the direction of the current flowing through the coil 
according to the flowchart presented in the Fig. 1. The considered variables were the number of turns and the distance from the coil to the heated surface. In every case, particular turns were assumed to be serially connected. The most important material parameters that were used for simulation are shown in Table I.

In all cases, a $200 \mathrm{~mm}$ wide and $40 \mathrm{~mm}$ thick stamp insert was considered. A $100 \mathrm{~mm}$ wide forming surface was placed centrally.

Case A (Fig. 2 a, b) constitutes a commonly met example derived from industrial practice. In both cavities (matrix and stamp) made of ferromagnetic material (1.2343 steel) two, isolated by $1 \mathrm{~mm}$ air gap, windings were placed. This configuration allows more dynamic, in comparison to other RTC (Rapid Temperature Cycling) technologies, heating of forming walls.

In the analysed scenario, the distance from the coil to the heated surfaces was $10 \mathrm{~mm}$. Distance between windings was $25 \mathrm{~mm}$. Heating time was set on 10 seconds.
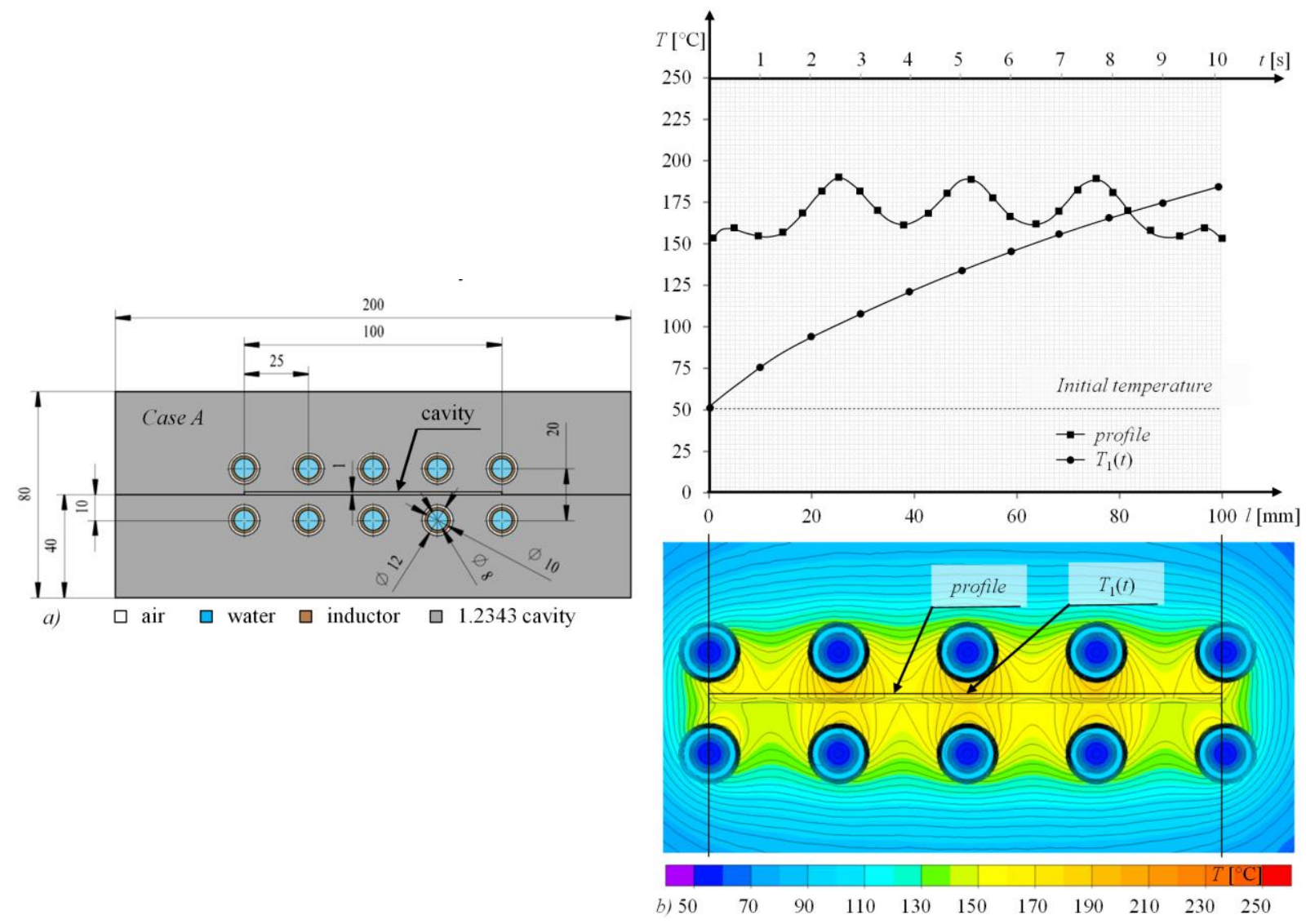

Figure 2: Case A: a) analysed scenario, b) results of induction heating process.

Fig. $2 \mathrm{~b}$ presents a temperature changes in time domain. 10 seconds after the start, there has been a growth of temperature of stamp forming walls $T_{1}(t)$ - from 50 to $192{ }^{\circ} \mathrm{C}$ with average rate of $14,2^{\circ} \mathrm{C} / \mathrm{s}$. In the figure a $100 \mathrm{~mm}$ long line is located, which corresponds to the width of forming cavity for which a temperature profile was calculated. That profile helped to determine temperature gradient of forming wall $\Delta T_{1}(t)$ of $38^{\circ} \mathrm{C}$. Such a great value of the gradient is most probably a result of a relatively large distance between coils windings. Similar problem was examined by Rhein et al. [27]. That solution has two fundamental drawbacks. Firstly, it requires a complex design what creates additional difficulties. Namely, the location of windings inside the stamp directly below the forming surface is not convenient for placing ejector system due to the lack of available space. The second problem is the temperature growth in the large volume of the mould what increase the cooling time, in comparison to surface heating methods. 
Author of this paper proposes to deliberately introduce a temperature gradient on the forming surface. It is not necessary to increase the cavity temperature in the areas where polymer flow problems do not occur. The results described in articles [15, 16] support this approach. The problem is to separate the forming surfaces intended for induction heating. In this work, multi-metallic mould cavities with variable magnetic properties were proposed.

Fig. 3 a shows a simplified model of the cavity made of hardened aluminium and ferromagnetic steel inserts 1.2343 in the areas designated for induction heating. An external 5 -turn inductive coil was placed $5 \mathrm{~mm}$ away from the flat forming surface. The second variant (Fig. 3 b) was modified by the application of a magnetic field concentrator, which was made of fluxtrol-type material. That material is characterized by its high magnetic permeability $\mu$ compared to other materials. This allows control (to some extent) of the direction of the magnetic field lines and concentrates them in the heated areas.
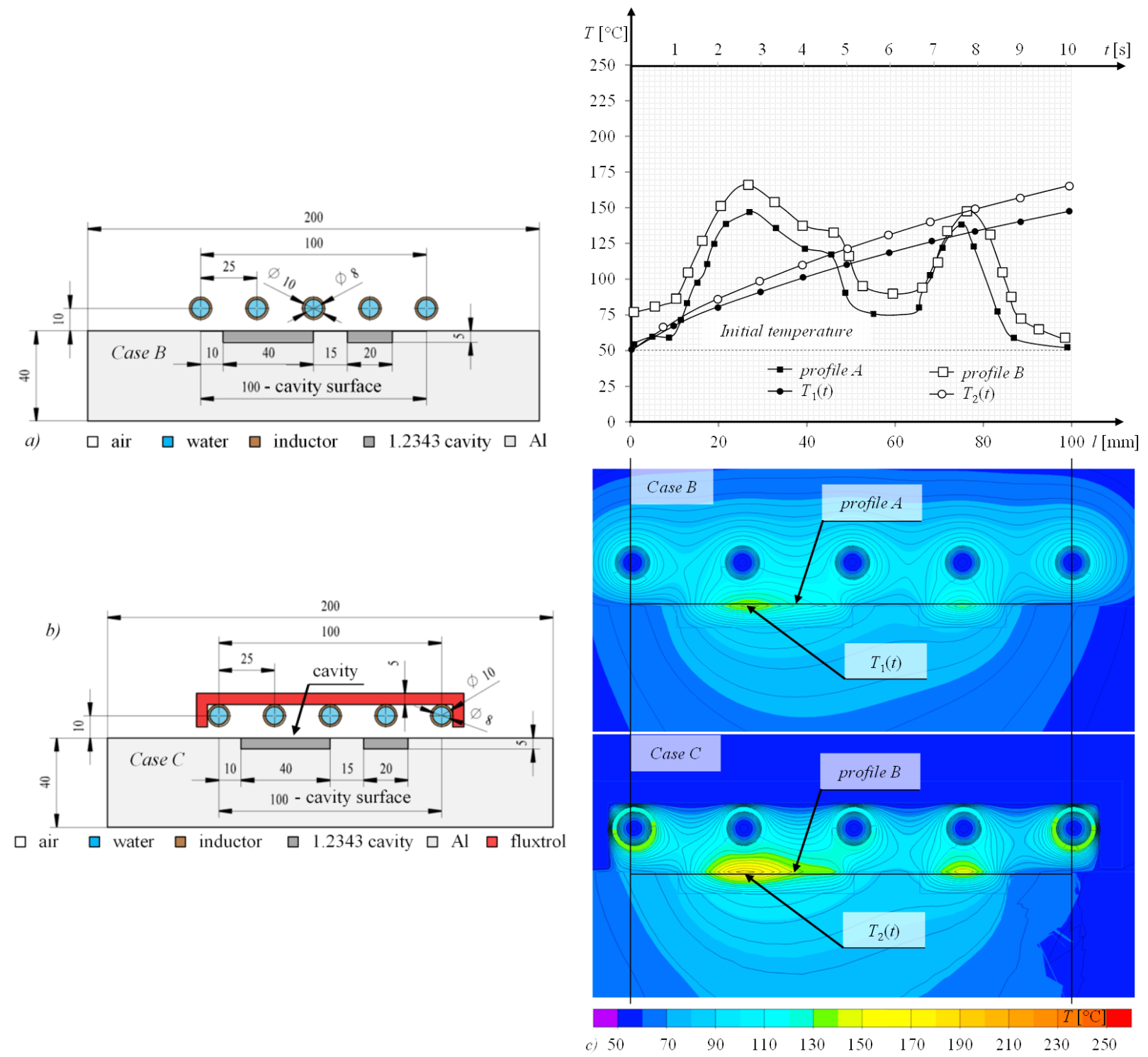

Figure 3: Analysed scenarios and results: a) case B, b) case C, c) results of induction heating for cases $\mathrm{B}$ and $\mathrm{C}$.

Fig. $3 \mathrm{c}$ depicts the results of simulations conducted for cases B and C. The graphs show the temperature distribution on the cavity forming wall after 10 second heating and corresponding temperature growth between 0 and 10 seconds. Despite the fact that the coils are distributed throughout the entire width of the forming cavity, only the surfaces in the areas 
made of 1.2343 steel are heated. The influence of individual turns on the mould temperature distribution can also be observed. Far-spaced located windings do not affect the heating process. The use of magnetic field concentrator has positively contributed to the efficiency of the heating process. The average temperature rise in the tested range reached $18{ }^{\circ} \mathrm{C}$ after 10 seconds.

In the next two cases (case D and E depicted in Fig. $4 \mathrm{a}$ and $4 \mathrm{~b}$ ), two extreme windings turns were removed. Still, the individual turns are connected in series, which means that the current of the exact intensity flows through them. The magnetic field concentrator was divided into two parts which correspond to the separated surfaces intended for induction heating. The purpose of this operation was to evaluate the control possibility of heating process in two separated areas of the injection mould using one induction coil. The windings of each coil were arranged symmetrically with respect to the individual ferromagnetic inserts.
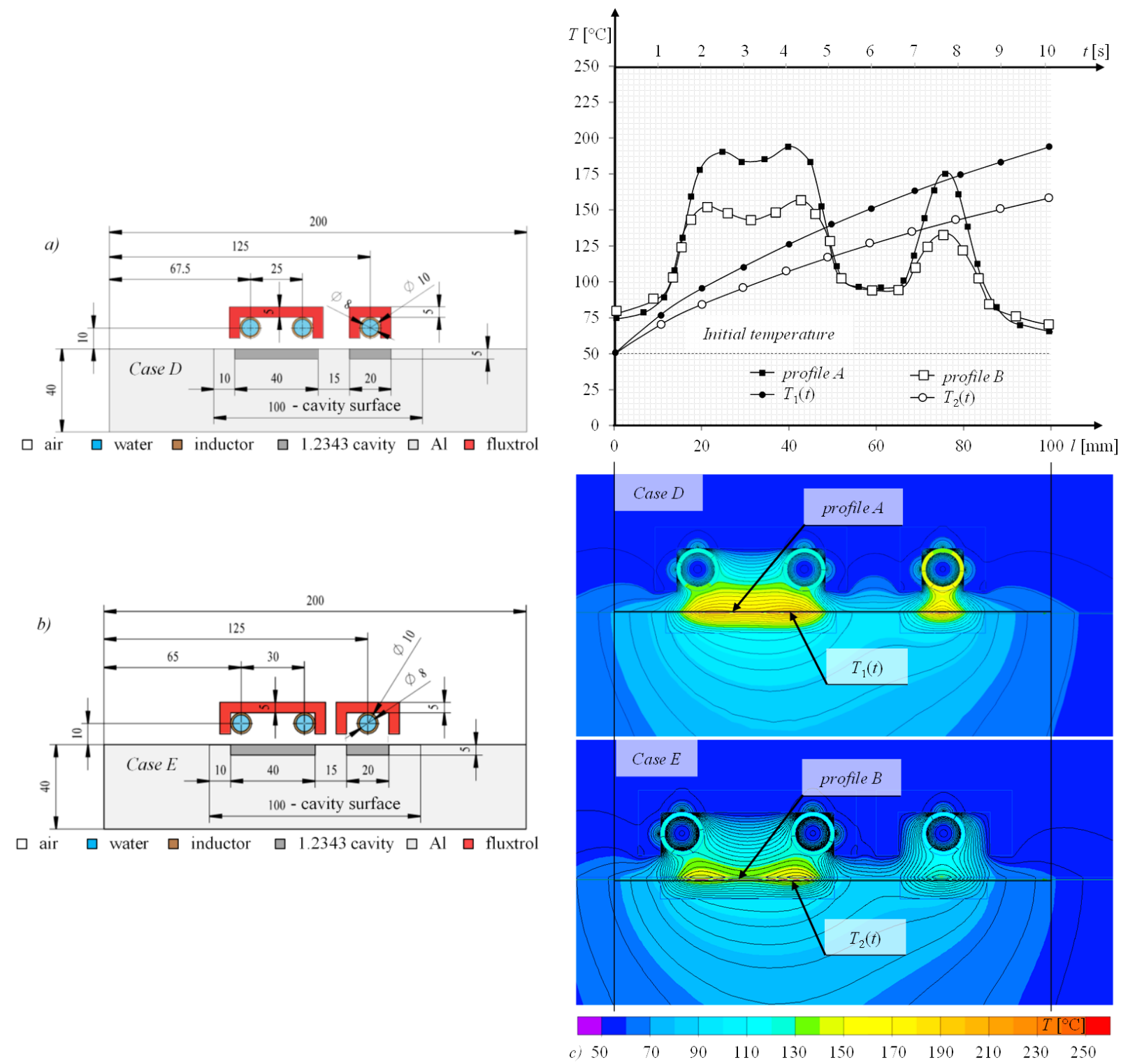

Figure 4: Analysed scenarios and results: a) case D, b) case E, c) results of induction heating for cases $\mathrm{D}$ and $\mathrm{E}$.

In case $\mathrm{E}$ the distance between the turns of the induction coil has been increased from 25 to $30 \mathrm{~mm}$. For the second heated area of a width of $20 \mathrm{~mm}$ the gap of the yoke was increased from 10 to $20 \mathrm{~mm}$. 
The results shown in Fig. $4 \mathrm{c}$ indicate that the application of two independent magnetic field concentrators has increased the efficiency of the heating process. After 10 seconds, the maximum temperature of $193{ }^{\circ} \mathrm{C}$ was obtained at point $T_{1}$. Extremes of temperature function are still evident and they correspond to the locations of the individual turns of the induction coil. As the distance from the coil axis projection to the heated surface increases, the dynamic temperature drop reaches $92{ }^{\circ} \mathrm{C}$ at the most distant ends of the ferromagnetic insert. It can be noticed that both the distance between the coil turns and the width of the concentrator gap affect the efficiency of the induction heating process. Increasing the distance between windings did not contribute to the decrease in the temperature gradient registered on the heated surface. Moreover, the efficiency of the heating process has decreased considerably from 14.3 to $10.8^{\circ} \mathrm{C} / \mathrm{s}$.

Further simulation studies were focused on determining the relationship of the temperature gradient and the distance between the coil and the heated surface (Fig. 5 a). A 3-winding induction coil and a $60 \mathrm{~mm}$ wide magnetic field concentrator were used so that its arms were outside the heated area. The main intention of this operation was to limit the negative effect of changing the coil distance from the heated surface, what affects the efficiency of the heating process. The distance between coil windings has been reduced to $20 \mathrm{~mm}$ so that the projections of far-sided turns axis coincide with the edges of the ferromagnetic insert located on the heated surface. The coil axis distance from the heated surface $l_{1}$ varied between 6 and $10 \mathrm{~mm}$. The warm-up time has been reduced to 2.5 seconds.
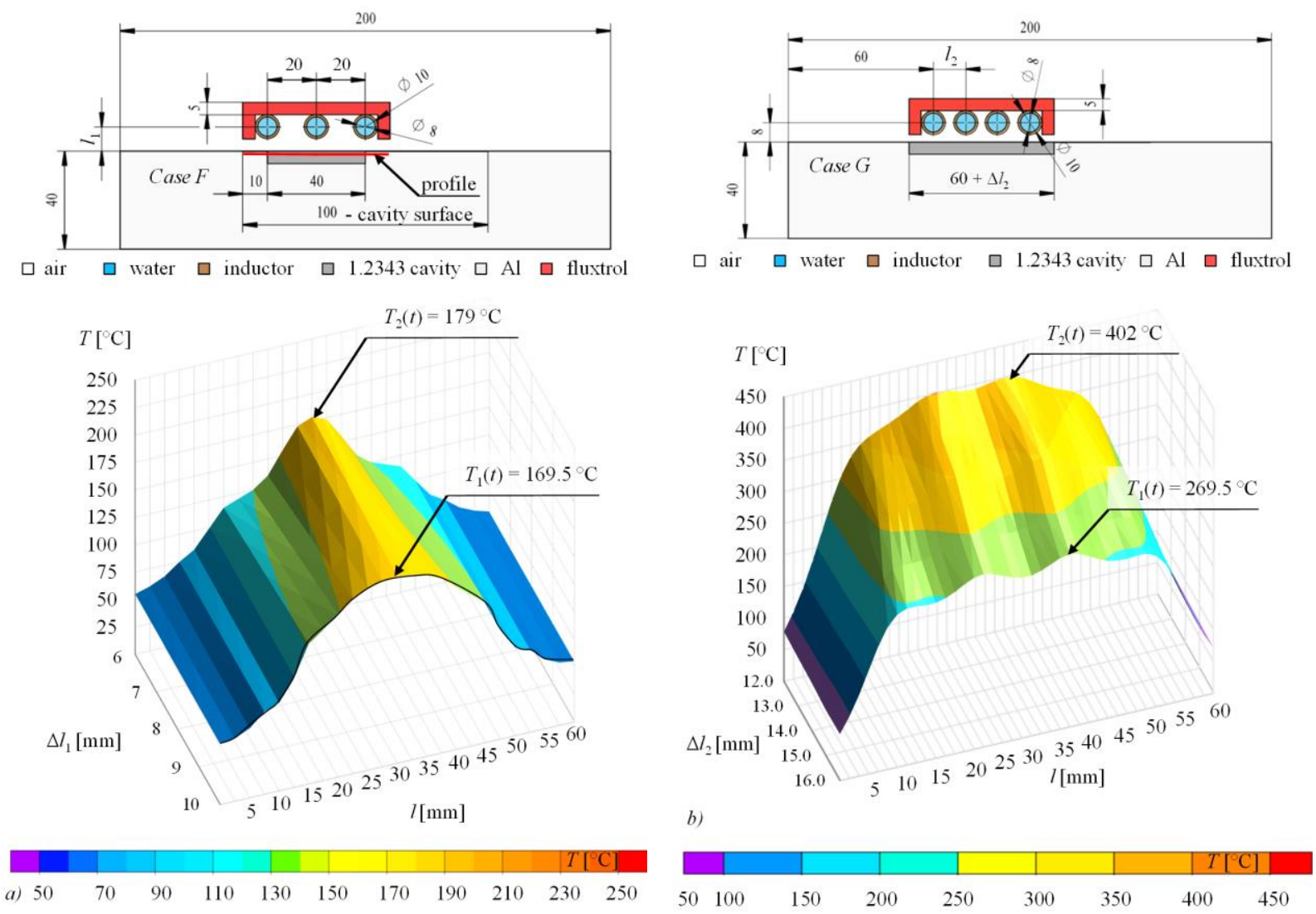

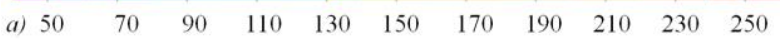

Figure 5: Geometry and results of induction heating process for: a) case F, b) case G.

The resulted temperature distribution (Fig. 5 a) refers only to the area of the forming cavity affected by the magnetic field concentrator. For all distances, there is an increase in the temperature at the point where 1.2343 steel inserts connects with aluminium alloy made part. The temperature gradient registered on the surface of the insert $114.5^{\circ} \mathrm{C}$ for $l_{1}=10 \mathrm{~mm}$ and $117^{\circ} \mathrm{C}$ for $l_{1}=6 \mathrm{~mm}$. Based on the thermographic image, a subtle effect can be observed at 
such a large distance between the turns. This concerns the impact of the change of the inductor distance from the surface of the forming cavity to the uniformity of the heating process. The temperature distribution is different for a significant reduction of the gap between each turns (Fig. 5 b).

In case $\mathrm{G}$, the axes of four coil turns were located $8 \mathrm{~mm}$ away from the heated surface. The distance between the axes of each turn varied between 12 and $16 \mathrm{~mm}$. In order to obtain a uniform temperature distribution on a $40 \mathrm{~mm}$ wide surface, the ferromagnetic insert width was increased to $60 \mathrm{~mm}$. Reducing the gap between individual turns significantly improved the process efficiency and decreased the temperature gradient registered on the heated surface.

The main contributing factors to such high efficiency, which is on average $140{ }^{\circ} \mathrm{C} / \mathrm{s}$ for $l_{2}=12 \mathrm{~mm}$ and $88^{\circ} \mathrm{C} / \mathrm{s}$ for $l_{2}=12 \mathrm{~mm}$, is undoubtedly the effect of decreasing the distance between the concentrator arms and the ferromagnetic insert. The relative magnetic permeability of air $\mu_{r}$ is equal to 1 and for fluxtrol the value reaches approximately 130 .

\section{CONCLUSION}

The work concerns problems related to the design of novel type of RTC injection moulds using electromagnetic induction. The author proposed the application of multi-metallic inserts in order to create a temperature gradient in the area of a single mould cavity. The general idea is to heat only those forming surfaces that are key to the flow of the molten polymer and thus, responsible for the potential part defects. The purpose of the simulations was not to solve a specific design problem but to show that it is possible to control the induction heating process in the area of a single injection mould cavity using only one induction coil. The research was also conducted in order to determine relations between the temperature distributions and the geometrical parameters of the system. Based on the obtained results, it can be stated that:

- It is possible to control the induction heating process in single mould cavity area using only one induction coil.

- The dynamics of the heating process and the temperature distribution on the forming surface are strictly dependent on the applied materials.

- It is possible to dynamically increase the temperature of the selected forming areas to the temperature of the molten polymer while minimizing the temperature of the remaining (adjacent) moulding surfaces. This affects the dynamics of the heating of the injection mould as presented in earlier studies [16, 17].

- When using the geometry of the induction coil that corresponds to the forming surface, it is possible to obtain a uniform temperature distribution on the heated surface.

- At the next stage of the research, experimental verification will be carried out. As a current source, $10 \mathrm{~kW}$ induction generator EFD Minac 6 will be used. The parameters of the heating process will be related to the values assumed during the simulation. The temperature will be measured with Pt100 and thermal imaging camera Flir T620.

\section{ACKNOWLEDGEMENT}

The publication was created as a part of the project 02/22/DSPB/1431.

As an author, I would like to thank Professor Shia Chung Chen for kind substantive and editorial comments during the development of the article.

\section{REFERENCES}

[1] Agazzi, A.; Sobotka, V.; LeGoff, R.; Jarny, Y. (2014). Inverse method for the cooling system design in injection moulding - application to a 'T-shaped' piece, Inverse Problems in Science and Engineering, Vol. 22, No. 5, 707-726, doi: 10.1080/17415977.2013.823412 
[2] Chen, S.-C.; Lin, Y.-W.; Chien, R.-D.; Li, H.-M. (2008). Variable mold temperature to improve surface quality of microcellular injection molded parts using induction heating technology, Advances in Polymer Technology, Vol. 27, No. 4, 224-232, doi:10.1002/adv.20133

[3] Huang, C.-T.; Hsien, I.-S.; Tsai, C.-H.; Chiou, Y.-C.; Tang, C.-C. (2011). The effects of various variotherm processes and their mechanisms on injection molding, International Polymer Processing, Vol. 26, No. 3, 265-274, doi:10.3139/217.2436

[4] Su, Q.; Zhang, N.; Gilchrist, M. D. (2016). The use of variotherm systems for microinjection molding, Journal of Applied Polymer Science, Vol. 133, No. 9, Paper 42962, 17 pages, doi:10.1002/app.42962

[5] Moritzer, E.; Seidel, S. (2015). Numerical analysis and evaluation of process and geometry specific transient temperature fields for a new variation of gas-assisted injection molding, International Polymer Processing, Vol. 30, No. 2, 265-275, doi:10.3139/217.3010

[6] Wang, W.; Zhao, G.; Guan, Y.; Wu, X.; Hui, Y. (2015). Effect of rapid heating cycle injection mold temperature on crystal structures, morphology of polypropylene and surface quality of plastic parts, Journal of Polymer Research, Vol. 22, No. 5, Paper 84, doi:10.1007/s10965-015$\underline{0731-5}$

[7] Homar, D.; Čerče, L.; Kopač, J. (2017). Cooling simulation of conformal cooling injection mould insert produced by hybrid manufacturing, Technical Gazette, Vol. 24, No. 4, 981-986, doi:10.17559/TV-20150909075338

[8] Croitoru, E.-I.; Magurian, D.; Oancea, G. (2016). Finite element analysis of heating-cooling systems used for laminating tools, Transactions of FAMENA, Vol. 40, No. 1, 111-128

[9] Lucchetta, G.; Fiorotto, M. (2013). Influence of rapid mould temperature variation on the appearance of injection-moulded parts, Strojniski vestnik - Journal of Mechanical Engineering, Vol. 59, No. 11, 683-688, doi:10.5545/sv-jme.2013.1001

[10] Hsu, F. H.; Wang, K.; Huang, C. T.; Chang, R. Y. (2013). Investigation on conformal cooling system design in injection molding, Advances in Production Engineering \& Management, Vol. 8, No. 2, 107-115, doi:10.14743/apem2013.2.158

[11] Wada, A.; Tazaki, K.; Tahara, T.; Suzuki, H.; Mizutani, Y. (1982). Injection molded articles with improved surface characteristics, US Patent No. 4439492

[12] Chen, S. C.; Peng, H. S.; Chang, J. A.; Jong, W. R. (2004). Simulations and verifications of induction heating on a mold plate, International Communications in Heat and Mass Transfer, Vol. 31, No. 7, 971-980, doi:10.1016/j.icheatmasstransfer.2004.05.007

[13] Chen, S.-C.; Jong, W.-R.; Chang, J.-A. (2006). Dynamic mold surface temperature control using induction heating and its effects on the surface appearance of weld line, Journal of Applied Polymer Science, Vol. 101, No. 2, 1174-1180, doi:10.1002/app.24070

[14] Chen, S.-C.; Jong, W.-R.; Chang, Y.-J.; Chang, J.-A.; Cin, J.-C. (2006). Rapid mold temperature variation for assisting the micro injection of high aspect ratio micro-feature parts using induction heating technology, Journal of Micromechanics and Microengineering, Vol. 16, No. 9, 17831791, doi:10.1088/0960-1317/16/9/005

[15] Mrozek, K.; Staniek, R.; Szostak, M. (2014). Research on external and internal induction heating effectiveness of injection molds by means of thermovision measurements, Proceedings of the ASME $12^{\text {th }}$ Biennial Conference on Engineering Systems Design and Analysis (ESDA), Vol. 3, Paper No. ESDA2014-20317, 6 pages, doi:10.1115/ESDA2014-20317

[16] Mrozek, K.; Chen, S.-C. (2017). Selective induction heating to eliminate the fundamental defects of thin-walled moldings used in electrical industry, Journal of Applied Polymer Science, Vol. 134, No. 26, Paper 44992, doi:10.1002/app.44992

[17] Mrozek, K. (2015). Optimization of injection mold design through application of external selective induction heating, ASME Proceedings of the $20^{\text {th }}$ Design for Manufacturing and the Life Cycle Conference ASME, Paper No. DETC2015-46440, 9 pages, doi:10.1115/DETC2015-46440

[18] Theilade, U. A.; Hansen, H. N. (2007). Surface microstructure replication in injection molding, International Journal of Advanced Manufacturing Technology, Vol. 33, No. 1-2, 157-166, doi:10.1007/s00170-006-0732-y

[19] Xie, L.; Niesel, T.; Leester-Schadel, M.; Ziegmann, G.; Buttgenbach, S. (2013). A novel approach to realize the local precise variotherm process in micro injection molding, Microsystem Technologies, Vol. 19, No. 7, 1017-1023, doi:10.1007/s00542-012-1692-9 
[20] Wang, G.-L.; Zhao, G.-Q.; Li, H.-P.; Guang, Y.-J. (2009). Research on a new variotherm injection molding technology and its application on the molding of a large LCD panel, PolymerPlastics Technology and Engineering, Vol. 48, No. 7, 671-681, doi:10.1080/03602550902824549

[21] Du, H.; Li, J.-Y.; Qu, Y.-B. (2014). Mathematical modeling of eddy-current loss for a new induction heating device, Mathematical Problems in Engineering, Vol. 2014, Paper ID 923745, 7 pages, doi: $10.1155 / 2014 / 923745$

[22] Rapoport, E.; Pleshivtseva, Y. (2006). Optimal Control of Induction Heating Process, CRC Press, Boca Raton

[23] Yang, L.; Zheng, M. L. (2017). Simulation and analysis of ball-end milling of panel moulds based on Deform 3D, International Journal of Simulation Modelling, Vol. 16, No. 2, 343-356, doi:10.2507/IJSIMM16(2)CO9

[24] Ko, D.-C.; Min, G.-S.; Kim, B.-M.; Choi, J.-C. (2000). Finite element analysis for the semi-solid state forming of aluminium alloy considering induction heating, Journal of Materials Processing Technology, Vol. 100, No. 1-3, 95-104, doi:10.1016/S0924-0136(99)00459-8

[25] Eom, H.; Park, K.; (2009). Fully-coupled numerical analysis of high-frequency induction heating for thin-wall injection molding, Polymer-Plastics Technology and Engineering, Vol. 48, No. 10, 1070-1077, doi:10.1080/03602550903092484

[26] Liu, X. H. (1994). Rigid plastic FEM and its application in rolling, Metallurgy Industry Press, Beijing, 300-324

[27] Rhein, S.; Utz, T.; Graichen, K. (2015). Optimal control of induction heating process using FEM software, Proceedings of the 2015 European Control Conference (ECC), 515-520, doi:10.1109/ECC.2015.7330595 